\section{Moderate to severe obstructive sleep apnoea patients is associated with a higher incidence of visual field defect}

\begin{abstract}
Purpose To compare the visual fields (VFs) and optic nerve head changes between obstructive sleep apnoea (OSA) in normotensive patients and an age-matched non-OSA population.

Design Case-control study.

Participants A total of 41 ethnic Chinese patients diagnosed with moderate to severe OSA referred from the Sleep Laboratory, ENT Department, Tuen Mun Hospital. A total of 35 age-matched non-OSA subjects recruited from the Ophthalmology Department, North District Hospital.

Methods Comprehensive ophthalmological and systemic history, complete ophthalmological examination, including central-30 computerized perimetry for all studied patients.

Main outcome measures Polysomnographic data, VF indices, optic disc changes Results In the OSA arm, VF indices were significantly subnormal and the incidence of suspicious glaucomatous disc changes was four times higher than that of the control arm. None of the studied patients suffered from any form of anterior segment complications. Conclusions Moderate to severe OSA is associated with a higher incidence of VF defect and glaucomatous optic nerve changes. Eye (2006) 20, 38-42. doi:10.1038/sj.eye.6701785; published online 14 January 2005
\end{abstract}

Keywords: obstructive sleep apnoea; optic neuropathy; visual field; optic disc

Received: 16 August 2004 Accepted in revised form: 21 October 2004;

Published online:

14 January 2005

Proprietary interest: Nil Financial support: Nil
Obstructive sleep apnoea (OSA) is a disease that is characterized by repetitive episodes of upper airway collapse during sleep. Apnoea is defined

\section{Introduction}

CSL Tsang ${ }^{1}$, SL Chong ${ }^{1}$, CK Ho ${ }^{1}$ and MF Li

as cessation of oro-nasal flow for a duration of $10 \mathrm{~s}$ or more. Hyponoea is defined as reduction of oro-nasal flow for greater than $50 \%$ associated with a $4 \%$ of oxygen desaturation. The apnoeic hypopnoeic index (AHI) is the sum of the apnoea and hypopnoea events during an hour of sleep and is used to grade the severity of OSA. Patient is diagnosed to have OSA if the $\mathrm{AHI}$ is $\geqslant 5$. Mild OSA has an AHI between 5 and 20. Moderate OSA has an AHI of 20 to less than 40. Severe OSA has an AHI $\geqslant 40 .{ }^{1-4}$ OSA is well known to result in a number of health consequences: fragmentation of sleep leads to chronic sleep deprivation and daytime somnolence, hence affecting the patients' daily cognitive function and quality of life, increasing incidences of work-related and motor vehicle accidents; cardio-respiratory disturbances lead to elevated risks of complications such as hypertension, pulmonary hypertension, cardiac arrhythmia, myocardial infarction, congestive cardiac failure, and stroke. ${ }^{1-6}$ Recently, possible ocular manifestations, including optic neuropathy in the form of visual field (VF) defect and disc oedema, normal-tension glaucoma (NTG), pseudotumour cerebri, nonarteritic anterior ischaemic optic neuropathy (NAAION); and anterior segment complications such as floppy eyelid syndrome, upper lid ptosis, lower lid ectropion, blepharochalasis, trichiasis, chronic conjunctivitis, keratoconus, exposure keratopathy, dry eyes, recurrent corneal erosion (RCE), keratitis, and progressive endotheliopathy have aroused ophthalmologists' concern. ${ }^{7-15}$ However, there are limited evidences in published articles of causal relationship between OSA and the various ocular manifestations, especially in the Chinese locality. Therefore, we designed a prospective case-control study to continuously 
recruit OSA patients, follow them up to determine the prevalence of ocular manifestations, and observed their progress. To detect any presence of suspected OSArelated optic neuropathy, we focus only on confirmed moderate to severe OSA cases and exclude high-tension glaucomatous cases. VF indices and the glaucomatous disc changes in the group of asymptomatic normotensive OSA patients were compared with a group of age- and sex-matched non-OSA patients. We believed that continuous collection and follow-up of OSA patients would give valuable information on whether the VF and optic disc changes are progressive and associated with OSA, and whether they are reversible with treatment of the OSA condition. We might also be able to demonstrate causal relationship between OSA and NTG, ischaemic optic neuropathy or other disease entities.

\section{Method}

We recruited 41 Chinese patients consecutively referred from the Sleep laboratory, Department of ENT, Tuen Mun Hospital from November, 2002 to July, 2003. They were confirmed to have moderate to severe OSA $(\mathrm{AHI} \geqslant 20)$ on polysomnography (Alice 3 Healthdyne Technologies, USA). 35 consecutive age- and gender-matched non-OSA subjects with negative history of snoring or excessive daytime somnolence were recruited as control subjects from the Ophthalmology Clinic, North District Hospital. A comprehensive history and a thorough ophthalmological examination was conducted by a single ophthalmologist (SL). Cup: disc ratio was measured under slit-lamp biomicroscope. A central-30 Humphery perimetry with undilated pupils and corrected refractive errors were obtained. Spot applanation tonometry was performed to all recruited subjects. If suspicious VF or optic disc was found, a 24-hours' phasing test using tonopen would be performed in supine posture (rechecked using applanation tonometry in upright posture if intraocular pressure $>21 \mathrm{mmHg}$ ). ${ }^{16}$ Exclusion criteria for both arms included patients with known conditions which might affect VF result-high-tension glaucoma with intraocular pressure $\geqslant 21 \mathrm{mmHg}$, intracranial or intraorbital space occupying lesions, optic neuropathies, arteritic AION, optic disc abnormalities, significant media opacity, known history of hypotensive crisis, and vasospastic diseases. Unreliable VF tests with fixation loss $>15 \%$, false positives or false negatives $>15 \%$ were excluded. Patients with suspicious VF or disc changes were followed up and VF tests were repeated 2 months later for consistency. The more reliable field would be taken into account. Objective VF indices including the mean deviation (MD) and pattern standard deviation (PSD) were recorded. We studied the distribution of VF indices among the OSA and control arm and analysed the difference between the two arms using unpaired $t$-test. Within the OSA arm, Spearman's correlation test controlled for age and body mass index (BMI) was used to find if VF indices were significantly correlated to $\mathrm{AHI}$ and untreated duration of OSA, respectively. Incidence of suspicious disc changes with cup: disc ratio greater than 0.5 , signs of pathological disc changes like vertical cupping, rim notching, disc haemorrhage, or disc swelling in the two arms were compared using $\chi^{2}$ test. All statistic calculations were carried out using SPSS soft-ware Version 11.0 (SPSS Inc., Chicago, IL, USA).

\section{Results}

In all, 72 eyes of 36 OSA patients (OSA arm) are compared with 59 eyes of 30 age- and sex-matched nonOSA subjects (Control arm). Demographic data are summarized in Table 1. Ten eyes in the OSA arm and

Table 1 Demographic data of the OSA and control arm

\begin{tabular}{|c|c|c|}
\hline & OSA arm & $\begin{array}{c}\text { Control } \\
\text { arm }\end{array}$ \\
\hline Number of eyes recruited & $\begin{array}{l}82 \text { of } 41 \\
\text { patients }\end{array}$ & $\begin{array}{l}68 \text { of } 35 \\
\text { subjects }\end{array}$ \\
\hline $\begin{array}{l}\text { Number of eyes excluded } \\
\text { High tension glaucoma } \\
\text { Severely tilted disc } \\
\text { Significant media opacities } \\
\text { Unreliable VF } \\
\text { Lack of polysomnography data }\end{array}$ & $\begin{aligned} 10 & (12.20 \%) \\
3 & (3.66 \%) \\
1 & (1.22 \%) \\
0 & (0.00 \%) \\
0 & (0.00 \%) \\
6 & (7.32 \%)\end{aligned}$ & $\begin{array}{l}9(11.76 \%) \\
2(2.94 \%) \\
2(2.94 \%) \\
3(4.41 \%) \\
2(2.94 \%) \\
\quad \text { N/A }\end{array}$ \\
\hline Number of eyes studied & $72(87.80 \%)$ & $59(88.24 \%)$ \\
\hline $\begin{array}{l}\text { Gender } \\
\text { Male } \\
\text { Female }\end{array}$ & $\begin{array}{r}31(86.11 \%) \\
5(13.89 \%)\end{array}$ & $\begin{array}{r}26(86.66 \%) \\
4(13.34 \%)\end{array}$ \\
\hline $\begin{array}{l}\text { Age } \\
\text { Range } \\
\text { Mean }\end{array}$ & $\begin{array}{c}27-83 \\
48.0\end{array}$ & $\begin{array}{c}32-62 \\
44.5\end{array}$ \\
\hline $\begin{array}{l}\text { Body mass index }(\mathrm{BMI}) \\
\text { Range } \\
\text { Mean }\end{array}$ & $\begin{array}{c}24.2-40.8 \\
29.5\end{array}$ & $\mathrm{~N} / \mathrm{A}$ \\
\hline $\begin{array}{l}\text { AHI (Apnoea-hypnoea-index) } \\
\text { Range } \\
\text { Mean }\end{array}$ & $\begin{array}{c}21.0-149.7 \\
59.8\end{array}$ & $\mathrm{~N} / \mathrm{A}$ \\
\hline $\begin{array}{l}\text { No. of eyes in patients with } \\
\text { Moderate OSA (AHI > 20-40) } \\
\text { Severe OSA (AHI >40) }\end{array}$ & $\begin{array}{l}23(31.94 \%) \\
49(68.06 \%)\end{array}$ & \\
\hline $\begin{array}{l}\text { Duration of OSA } \\
\text { symptoms (untreated) } \\
\text { (years) range } \\
\text { Mean }\end{array}$ & $\begin{array}{c}0.5-20.0 \\
5.6\end{array}$ & $\mathrm{~N} / \mathrm{A}$ \\
\hline
\end{tabular}

OSA — obstructive sleep apnoea; VF—visual field; N/A — not applicable. 


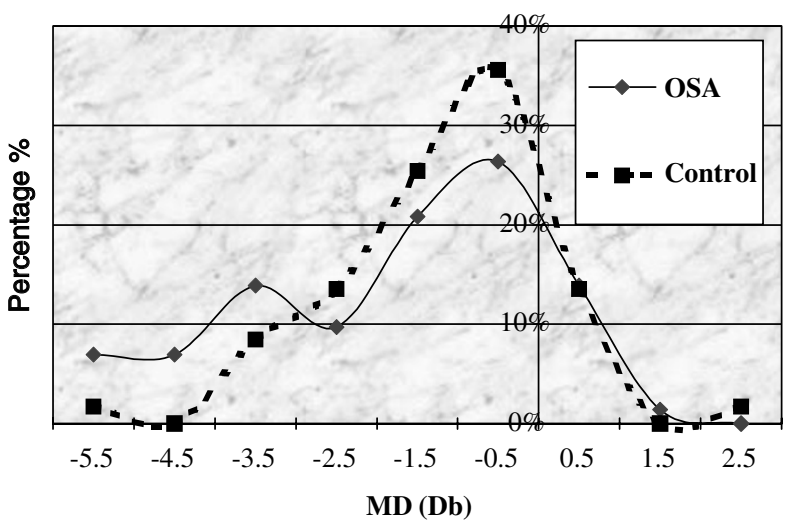

Figure 1 Distribution of MD in OSA and control arms Difference in MD between the OSA and control arms was statistically significant $(P<0.01)$ ( $t$-test). OSA - obstructive sleep apnoea, MD - mean deviation, $\mathrm{Db}$ - decibels.

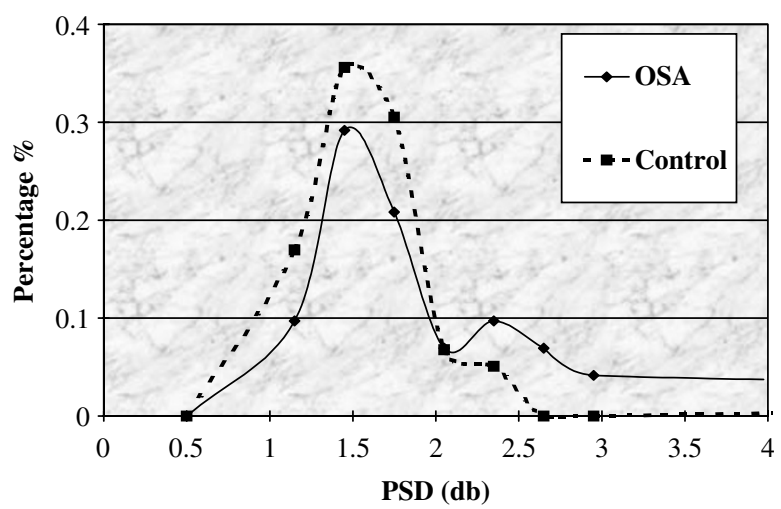

Figure 2 Distribution of PSD in OSA and control arms. Difference in PSD between the OSA and control arms was statistically significant $(P<0.01)(t$-test). OSA - obstructive sleep apnoea, PSD - pattern standard deviation, $\mathrm{Db}$ - decibels.

Table 2 Analysis of visual field performance in the OSA subjects

\begin{tabular}{lll}
\hline Spearman's correlation $(P)$ & $M D$ & $P S D$ \\
\hline Duration of OSA symptoms & 0.257 & 0.079 \\
Severity of OSA (AHI) & 0.052 & 0.903
\end{tabular}

$P>0.01$ shows no statistically significant correlation $(99 \%$ confidience interval).

OSA - obstructive sleep apnoea; MD - mean deviation; PSD — pattern standard deviation; AHI-apnoeic-hypopnoeic index.

nine eyes in the control arm were excluded according to the above-stated exclusion criteria. Within the OSA arm, $30 \%$ of studied eyes were in the group of patients with moderate $(\mathrm{AHI}<40)$, and $70 \%$ with severe $(\mathrm{AHI} \geqslant 40)$ OSA. The mean duration of OSA symptoms without treatment was 5.6 years (range $0.5-20.0$ years).

Figures 1 and 2 compare the distribution of VF indices between the OSA and control arm. There was a second peak of suboptimal MD at $-3.5 \mathrm{MD}$ in the OSA arm as compared to the normally distributed MD in the control arm. The distribution of PSD in the OSA arm was skewed away from the norm when compared to the control arm. The differences in VF indices (both MD and PSD) between the OSA and control arms were statistically significant $(P<0.01)$.

Table 2 shows the results of statistical analysis of the VF indices within the OSA arm. No statistically significant correlation was found between the VF indices, the AHI, and the untreated duration of OSA in our study.

In Table 3, the incidence of suspicious glaucomatous disc changes in OSA arm was four times higher when compared to its control arm (26.39 against 6.78\%), which was found to be statistically significantly different $(P=0.001,99 \% \mathrm{CI})$. However, there was no statistically significant difference found within the subgroups with moderate against severe OSA as shown in Table 4 $(P=0.944)$. Table 5 shows that there was no statistically significant difference between the incidences of hightension glaucoma in OSA and Control arm $(P=0.765)$.

None of the studied patients had anterior segment complications like floppy eyelid syndrome, upper lid

Table 3 Incidence of suspicious disc change in OSA and control arms

\begin{tabular}{lcc}
\hline & OSA arm & Control arm \\
\hline Normal discs & $53(73.61 \%)$ & $55(93.22 \%)$ \\
& & \\
Suspicious discs & $19(26.39 \%)$ & $4(6.78 \%)$ \\
$\quad$ Glaucomatous changes & $17(23.61 \%)$ & $4(6.78 \%)$ \\
Disc swelling & $2(2.78 \%)$ & $0(0.00 \%)$ \\
\hline
\end{tabular}

OSA —obstructive sleep apnoea; CI—confidience interval.

Table 4 Incidence of suspicious disc change in the OSA arm

\begin{tabular}{lrr}
\hline & Moderate OSA & Severe OSA \\
\hline Normal disc & $17(73.91 \%)$ & $36(73.47 \%)$ \\
Suspicious disc & $6(26.09 \%)$ & $13(26.53 \%)$
\end{tabular}

No statistical significance $(P=0.944), 95 \%$ CI ( $\chi^{2}$ test).

OSA - obstructive sleep apnoea, $\mathrm{CI}$-confidience interval

Table 5 Incidence of excluded cases due to high tension glaucoma

\begin{tabular}{lcc}
\hline & OSA & Control \\
\hline High IOP & $3(4.17 \%)$ & $2(3.39 \%)$ \\
Normal IOP & $69(95.83 \%)$ & $57(96.61 \%)$
\end{tabular}

No statistical significance difference $(P=0.765), 95 \% \mathrm{CI}\left(\chi^{2}\right.$ test). OSA-obstructive sleep apnoea; IOP-intraocular pressure; $\mathrm{CI}$ - confidience interval. 
ptosis, lower lid ectropion, blepharochalasis, trichiasis, chronic conjunctivitis, keratoconus, exposure keratopathy, significant dry eyes, RCE, keratitis, or progressive endotheliopathy.

\section{Discussion}

Our study is the relatively largest sample-sized, casecontrol study comparing 72 eyes in confirmed moderate to severe OSA patients with a normal control group of 59 eyes. The results in our study showed a significant deviation of VF indices from norm and a higher incidence of suspicious glaucomatous optic disc in the OSA arm when compared to the age- and gendermatched non-OSA control arm. Argument on possibility of suboptimal VF performance by an OSA patient due to sleepiness during the test is excluded in our study as the entire examination was observed by a single, experienced technician. Moreover, VFs with fixation losses, false positives or false negatives of more than $15 \%$ were excluded and repeated. Although our current study is limited by its short duration and observational nature, a hypothesis that OSA causes the optic neuropathies is not without rationale. Repetitive apnoeas might lead to direct anoxic damage to the optic nerve, or indirect effect on optic nerve head blood flow. The latter might be secondary to (1) sympathetic surge-induced arterial hypertension and hypertensive arteriosclerosis, (2) vascular dysregulation due to imbalance between nitric oxide (vasodilator) and endothelin (vasoconstrictor), (3) abnormal platelet aggregation and activation leading to microinfarcts in the optic nerve, or (4) episodic-raised intracranial pressure. ${ }^{6,15,17,18}$ The absence of statistically significant differences between the incidences of hightension glaucoma in the OSA arm $(3.66 \%)$ and control arm $(2.94 \%)$ in our study, speaks against the hypothesis of unrecognized, nocturnal high-tension glaucoma as a cause of the optic neuropathy, which was suggested by Marcus et al. ${ }^{12}$

If the above hypothesis stands, logical questions follow: whether more severe form and longer duration of OSA would lead to more severe neuropathies, and whether the optic neuropathies can be reversible with treatment? In our study, we did not find any statistically significant positive correlation between the AHI and VF performance/disc changes as reported by Mojon et al ${ }^{9,10}$ However, we have only included the moderate to severe OSA patients while leaving out the mild cases. Moreover, the majority $(70 \%)$ of our studied cases suffered from severe OSA. Thus our study cannot rule out the presence of such a correlation. We did not find any statistically significant correlation between the duration of OSA and VF performance. However, the data duration of OSA was subjectively recalled by the patients and may not be totally reliable. Longer follow-up of more OSA patients would give valuable information on the progress of their $\mathrm{VF}$ and disc changes, whether the changes are reversible with treatment of the OSA condition, and whether OSA is associated causally with NTG, ischaemic optic neuropathy, or other disease entities.

Nevertheless, as found in our demographic data and Mohsenin et al paper, moderate to severe OSA most commonly occurs in middle aged male, who constitute the productive population in a society. ${ }^{19}$ Therefore, the role of ophthalmologists in early screening for potentially blinding optic neuropathies in this group of patients is worthwhile from an economic standpoint. On the contrary, while encountering patients with unknown cause of optic neuropathies, some of them being diagnosed with and treated as NTG, it might be worthwhile to ask for a sleep history and refer suspicious cases for further investigations for OSA.

\section{Conclusion}

OSA is associated with a higher incidence of VF defect and glaucomatous optic disc changes in a group of Chinese normotensive patients.

\section{References}

1 Krug P. Snoring and obstructive sleep apnea. Ass Operating Room Nurses J 1999; 69: 792-801.

2 Guilleminault C, Stoohs R, Clerk A, Cetel M, Maistros P. A cause of excessive daytime sleepiness. The upper airway resistance syndrome. Chest 1993; 104: 781-787.

3 Masood A, Phillips B. Sleep apnoea. Curr Opin Pulmonary Med 2000; 6: 479-484.

4 Flemons WW. Obstructive sleep apnea. New Engl J Med 2002; 34: 498-504.

5 Akashiba T, Kawahara S, Akahoshi T, Omori C, Saito O, Majima T et al. Relationship between quality of life and mood or depression in patients with severe obstructive sleep apnea syndrome. Chest 2002; 22: 861-865.

6 Siebler M, Nachtmann A. Cerebral hemodynamics in obstructive sleep apnea. Chest 1993; 103: 1118-1119.

7 Walsh JT, Montplaisir J. Familial glaucoma with sleep apnoea: a new syndrome? Thorax 1982; 37: 845-849.

8 Wolin MJ, Brannon WL. Disk edema in an overweight woman. Surv Ophthalmol 1995; 39: 307-314.

9 Mojon DS, Mathis J, Zulauf M, Koerner F, Hess CW. Optic neuropathy associated with sleep apnea syndrome. Ophthalmology 1998; 105: 874-877.

10 Mojon DS, Hess CW, Goldblum D, Fleischhauer J, Koerner F, Bassetti C et al. High prevalence of glaucoma in patients with sleep apnea syndrome. Ophthalmology 1999; 106: 1009-1012.

11 Mojon DS, Hess CW, Goldblum D, Boehnke M, Koerner F. Normal-tension glaucoma is associated with sleep apnea syndrome. Ophthalmologica 2002; 216: 180-184. 
12 Marcus DM, Costarides AP, Gokhale P, Papastergiou G. Sleep disorders: a risk factor for normal-tension glaucoma? J Glaucoma 2001; 10: 177-183.

13 Mojon DS, Hedges TR, Ehrenberg B, Karam EZ, Goldblum D et al. Association between sleep apnea syndrome and nonateritic anterior ischaemic optic neuropathy. Arch Ophthalmol 2002; 120: 601-605.

14 Lee AG, Golnik K, Kardon R, Wall M, Eggenberger E, Yedavally S. Sleep apnea and Intracranial Hypertension in Men. Ophthalmology 2002; 109: 482-485.

15 Mojon DS, Goldblum D, Fleischhauer J, Chiou AGY, Frueh $\mathrm{BE}, \mathrm{Hess} \mathrm{CW}$ et al. Eyelid, conjunctival, and corneal findings in sleep apnea syndrome. Ophthalmology 1999; 106: 1182-1185.

16 Santos MG, Makk S, Berghold A, Eckhardt M, Hass A. Intraocular pressure difference in Goldmann applanation tonometry versus Perkins hand-held applanation tonometry in overweight patients. Ophthalmology 1998; 105: $2260-2263$.

17 Hayreh SS, Zimmerman MB, Podhajsky P, Alward WL. Nocturnal arterial hypotension and its role in optic nerve head and ocular ischemic disorders. Am J Ophthalmol 1994; 117: 603-624.

18 Bokinsky G, Miller M, Ault K, Husband P, Mitchell J. Spontaneous platelet activation and aggregation during obstructive sleep apnea and its response to therapy with nasal continuous positive airway pressure. A preliminary investigation. Chest 1995; 108: 625-630.

19 Mohsenin V. Gender differences in the expression of sleepdisordered breathing: role of upper airway dimensions. Chest 2001; 120: 1442-1447. 